\title{
Sistem Pendukung Keputusan Pemilihan Mekanik Sepeda Motor Yamaha Alfascorfii Dengan Metode Multi Objective Optimization On The Basis Of Ratio Analysis (MO0RA)
}

\author{
M. Safiii1), Azlan Zulhamsyah ${ }^{2)}$ \\ ${ }^{1}$ AMIK Tunas Bangsa, Pematangsiantar \\ ${ }^{2}$ STIKOM Tunas Bangsa, Pematangsiantar \\ Jl. Jend. Sudirman Blok A No.1-3 Pematangsiantar \\ m.safii@amiktunasbangsa.ac.id, azlanzulhamsyah@gmail.com
}

\begin{abstract}
Job performance is one of the needs in a company. The demand for these needs aims to foster consumer confidence in the services provided. In service business activities such as the sale and service of professional motorbikes, mechanical work is needed. In determining the best mechanic, there are many criteria that the mechanic must fulfill. These criteria include efforts to overcome problems, years of service, education and discipline. The selection of the best motorcycle mechanics is done to help improve the mechanical workability to be better than before. To assist with the determination or selection in determining someone who deserves to be the best motorcycle mechanic, a decision support system is needed. In this study a case will be raised which is looking for the best alternative based on the criteria that have been determined by using the Multi Objective Optimization Method On The Base Of Ratio Analysis (MOORA). The research was conducted by looking for weight values for each attribute, then ranking process was carried out which would determine the optimal alternative, namely Yamaha Alfascorfii motorcycle mechanics.
\end{abstract}

Keywords: Decision Support Systems, Mechanics, MOORA, Motorbikes.

\begin{abstract}
Abstrak
Prestasi kerja merupakan salah satu kebutuhan dalam sebuah perusahaan. Tuntutan akan kebutuhan tersebut bertujuan untuk menumbuhkan kepercayaan konsumen terhadap pelayanan yang diberikan. Dalam kegiatan usaha jasa seperti penjualan dan service sepeda motor profesional kerja mekanik sangat dibutuhkan. Dalam menentukan mekanik terbaik, banyak sekali kriteria-kriteria yang harus dipenuhi oleh mekanik. Kriteria tersebut antara lain upaya mengatasi permasalahan, masa kerja, pendidikan dan disiplin. Pemilihan mekanik sepeda motor terbaik ini dilakukan untuk membantu meningkatkan daya kerja mekanik agar menjadi lebih baik lagi dari yang sebelumnya. Untuk membantu penentuan ataupun pemilihan dalam menetapkan seseorang yang layak menjadi mekanik sepeda motor terbaik maka dibutuhkan sebuah sistem pendukung keputusan. Pada penelitian ini akan diangkat suatu kasus yaitu mencari alternatif terbaik berdasarkan kriteria-kriteria yang telah ditentukan dengan menggunakan metode Multi Objective Optimization On The Basis Of Ratio Analysis (MOORA). Penelitian dilakukan dengan mencari nilai bobot untuk setiap atribut, kemudian dilakukan proses perankingan yang akan menentukan alternatif yang optimal, yaitu mekanik sepeda motor Yamaha Alfascorfii.
\end{abstract}

Kata kunci: Sistem Pendukung Keputusan, Mekanik, MOORA, Sepeda Motor.

\section{PENDAHULUAN}

Sistem pendukung keputusan berupa sistem yang berbasis komputer yang digunakan untuk mempermudah dalam melakukan pengambilan keputusan[1]. Pengunaan sistem pendukung keputusan membantu para 
pengambil keputusan dalam menghasilkan suatu keputusan. Hingga saat ini perkembangan metode-metode yang diterapkan pada sistem pengambil keputusan sangat pesat, dimulai dari metode yang sederhana hingga ke yang kompleks. Pada penelitian ini, metode yang digunakan yaitu MOORA. Pemanfaatan sistem pendukung keputusan dengan menggunakan metode MOORA sangat tepat jika diterapkan untuk memilih mekanik sepeda motor terbaik pada Yamaha Alfa Scorpii. Mekanik merupakan orang yang bertugas melakukan pemeriksaan, perawatan, perbaikan, penggantian suku cadang sesuai analisa Sevice Advisor yang tercantum dalam perintah kerja bengkel, dengan mengacu standarisasi pekerjaan yang telah ditetapkan dan beberapa kriteria yaitu penguasaan materi, praktek kerja, dan trouble shooting [2]. Tanpa disadari kriteria yang lain seperti surat teguran, masa kerja, dan pendidikan juga termasuk dalam penentuan pemilihan mekanik sepeda motor terbaik.

Penggunaan beberapa kriteria tersebut, diharapkan menghasilkan keputusan mekanik sepeda motor terbaik. Dengan penerapam metode ini diharapkan perusahaan dapat meningkatkan pelayanan kepada konsumen dan mekanik dapat bekerja dengan profesional menerapkan prinsip-prinsip kerja yang baik dan cerdas. Hasil capaian dari metode ini dapat meningkatkan daya saing dan kompetensi bagi mekanik untuk terus meningkatkan kemampuannya.

\section{METODOLOGI PENELITIAN}

\subsection{Sistem Pendukung Keputusan}

Manusia merupakan bagian dari alam karena hidupnya yang tidak terlepas dari alam. Proses kehidupan manusia merupakan unsur yang semakin lama semakin mendominasi unsur-unsur lainnya di alam. Hal ini disebabkan karena manusia dibekali kemampuan-kemampuan untuk bisa berkembang. Segala proses yang terjadi di sekelilingnya dan dalam dirinya dirasakan dan diamatinya dengan menggunakan semua indera yang dimilikinya, dipikirkannya lalu berbuat dan bertindak. Dalam menghadapi segala proses yang terjadi disekelilingnya dan di dalam dirinya, hampir setiap saat manusia membuat atau mengambil keputusan dan melaksanakannya. Hal ini dilandasi dengan asumsi bahwa segala tindakan dilakukan secara sadar merupakan pencerminan hasil proses pengambilan keputusan dalam pikirannya, sehingga sebenarnya manusia sudah sangat terbiasa dalam membuat keputusan[3].

\subsection{Mekanik}

Menurut Kamus Besar Bahasa Indonesia Pusat Bahasa mekanik yaitu ahli mesin. Mekanik adalah orang yang ahli dalam menggunakan perangkat keras untuk memperbaiki dan merawat mesin [4]. Kebanyakan mekanik mengkhususkan diri pada area tertentu seperti mekanik mobil, mekanik sepeda, mekanik sepeda motor, mekanik boiler, mekanik umum, pendingin udara dan pembekuan, mekanik pesawat terbang, mekanik mesin diesel. 


\subsection{Multi Objective Optimization On The Basis of Ratio Analysis (MOORA)}

Metode Multi Objective Optimization On The Basis Of Ratio Analysis( MOORA) adalah metode yang diperkenalkan oleh Brauers dan Zavadkas. Metode yang relatif baru ini pertama kali digunakan oleh Brauers dalam suatu pengambilan dengan multi kriteria [4]. Metode MOORA memiliki tingkat fleksibilitas dan kemudahan untuk dipahami dalam memisahkan bagian subjektif dari suatu proses evaluasi ke dalam kriteria bobot keputusan dengan beberapa atribut pengambilan keputusan. Metode ini memiliki tingkat selektifitas yang baik karena dapat menentukan tujuan dari kriteria yang bertentangan. Dimana kriteria dapat bernilai menguntungkan (benefit) atau yang tidak menguntungkan (cost). [5]

Metode MOORA banyak diaplikasikan dalam beberapa bidang seperti bidang manajemen, bangunan, kontraktor, desain jalan, dan ekonomi. Metode ini memiliki tingkat selektifitas yang baik dalam menentukan suatu alternatif. Pendekatan yang dilakukan MOORA didefinisikan sebagai suatu proses secarabersama anguna mengoptimalkan dua atau lebih yang saling bertentangan pada beberapa kendala. Langkah-langkah penyelesaian masalah menggunakan metode Multi Objective Optimization On The Basis of Ratio Analysis (MOORA), yaitu : [6]

1. Buat sebuah matriks keputusan

$$
\mathrm{X}=\left[\begin{array}{cccc}
x 11 & x 12 & \cdot & x 1 n \\
x 21 & x 11 & : & x 2 n \\
x m 1 & x m 1 & \cdot & x m n
\end{array}\right]
$$

2. Melakukan normalisasi terhadap matrik x

$$
\left.x i^{*} i j=x i j / \sqrt{\left[\sum_{i=1}^{m} x i^{2} i j\right](j}=1,2 \ldots, n\right)
$$

3. Mengoptimalkan Atribut

$$
Y_{i}=\sum_{j=1}^{g} X_{i j}^{*}-\sum_{j=g+1}^{n} X_{i j}^{*}
$$

Apabila menyertakan bobot dalam pencarian yang ternormalisasi maka rumusnya

$$
Y_{i}=\sum_{j=1}^{g} W_{j} X_{i j}^{*}-\sum_{j=g+1}^{n} W_{j} X_{i j}^{*}(j=1,2, \ldots . n)
$$

\section{HASIL DAN PEMBAHASAN}

Dalam menentukan pemilihan mekanik sepeda motor terbaik diperlukan beberapa cara atau pun metode dalam menentukannya. Pada penelitian sebelumnya pemilihan mekanik sepeda motor terbaik menggunakan beberapa kriteria yaitu penguasaan materi, praktek kerja, dan trouble shooting. Tapi tanpa disadari kriteria disiplin, masa kerja, dan pendidikan juga termasuk dalam penentuan pemilihan mekanik sepeda motor terbaik. Maka dari itu untuk membantu penentuan atau pun pemilihan dalam menetapkan seseorang yang layak menjadi seorang mekanik sepeda motor terbaik, dibutuhkan sebuah sistem pendukung keputusan untuk mengetahui hasil siapa yang akan menjadi mekanik terbaik. 
Adapun tujuan dari sistem pendukung keputusan pemilihan mekanik sepeda motor terbaik ini adalah untuk meningkatkan profesional kerja para mekanik dan membuat mekanik lebih baik lagi dari yang sebelumnya. Langkah penyelesaian dalam penerapan metode MOORA (Multi Objective Optimization On The Basis Of Ratio Analysis) antara lain:

\subsection{Memberikan nilai setiap alternative (Ai) pada setiap kriteria (Ci)} yang sudah ditentukan.

Tabel 1. Kriteria

\begin{tabular}{|c|c|c|c|}
\hline Kriteria & Keterangan & Bobot & Jenis \\
\hline C1 & Trouble Shooting & $30 \%$ & Benefit \\
\hline C2 & Masa Kerja & $30 \%$ & Benefit \\
\hline C3 & Pendidikan & $30 \%$ & Benefit \\
\hline C4 & Disiplin & $10 \%$ & Cost \\
\hline
\end{tabular}

1. Membuat matriks keputusan $X$

2. Melakukan normalisasi terhadap matrik x.

3. Memberi nilai bobot(W).

4. Mengoptimalkan atribut.

\subsection{Bobot penilaian}

Pemberian bobot penilaian dapat dilihat pada tabel 2 berikut:

Tabel 2. Skala Penilaian

\begin{tabular}{|c|c|c|c|}
\hline Kreteria & Keterangan & Keterangan & Nilai \\
\hline \multirow{4}{*}{ C1 } & \multirow{4}{*}{$\begin{array}{l}\text { Trouble } \\
\text { Shoting }\end{array}$} & Sangat Mahir & $91-100$ \\
\hline & & Mahir & $81-90$ \\
\hline & & Kurang Mahir & $70-81$ \\
\hline & & Tidak Bisa & $>70$ \\
\hline \multirow{3}{*}{$\mathrm{C} 2$} & \multirow{3}{*}{ Pendidikan } & Stara 1 & 5 \\
\hline & & Diploma 3 & 3 \\
\hline & & SMA/SMK & 1 \\
\hline \multirow{5}{*}{$\mathrm{C} 3$} & \multirow{5}{*}{ Masa Kerja } & $>1$ tahun & 5 \\
\hline & & 4 - 5 Tahun & 4 \\
\hline & & 3 - 4 Tahun & 3 \\
\hline & & $2-3$ tahun & 2 \\
\hline & & $<1$ tahun & 1 \\
\hline \multirow{4}{*}{$\mathrm{C} 4$} & \multirow{4}{*}{ Disiplin } & Sangat Baik & 4 \\
\hline & & Baik & 3 \\
\hline & & Kurang & 2 \\
\hline & & Sangat Kurang & 1 \\
\hline
\end{tabular}

\subsection{Hasil Penilaian Terhadap Kriteria}

Hasil penilaian terhadap masing-masing kriteria dapat dilihat pada tabel 3 berikut:

Tabel 3. Data Alternatif

\begin{tabular}{|c|c|c|c|c|}
\hline Alternatif & C1 & C2 & C3 & C4 \\
\hline A1 & 90 & 3 & 3 & 1 \\
\hline A2 & 95 & 3 & 5 & 1 \\
\hline A3 & 70 & 5 & 1 & 4 \\
\hline
\end{tabular}




\begin{tabular}{|c|c|c|c|c|}
\hline A4 & 80 & 5 & 3 & 3 \\
\hline A5 & 90 & 1 & 1 & 2 \\
\hline A6 & 80 & 3 & 3 & 1 \\
\hline
\end{tabular}

\subsection{Penyelesaian metode MOORA}

Langkah-langkah penyelesaian metode MOORA adalah sebagai berikut: a. Membuat matriks keputusan Xij

b. Normalisasi matriks $\mathrm{x}$

$$
X=\left[\begin{array}{llll}
90 & 3 & 3 & 1 \\
95 & 3 & 5 & 1 \\
70 & 5 & 1 & 4 \\
80 & 5 & 3 & 3 \\
90 & 1 & 1 & 3 \\
80 & 3 & 3 & 1
\end{array}\right]
$$

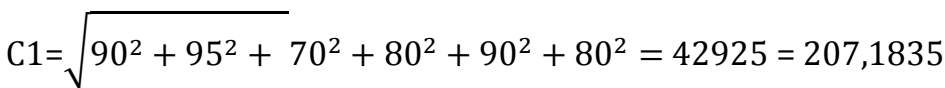

$\mathrm{A} 11=90 / 207,1835=0,434398$

$\mathrm{A} 21=95 / 207,1835=0,458531$

$\mathrm{A} 31=70 / 207,1835=0,337865$

$\mathrm{A} 41=80 / 207,1835=0,386131$

$\mathrm{A} 51=90 / 207,1835=0,434398$

$\mathrm{A} 61=80 / 204,45048=0,386131$

$C 2=\sqrt{3^{2}+3^{2}+5^{2}}+5^{2}+1^{2}+3^{2}=78=8,831761$

$\mathrm{A} 12=3 / 8,831761=0,339683$

$\mathrm{A} 22=3 / 8,831761=0,339683$

$\mathrm{A} 32=5 / 8,831761=0,566139$

$\mathrm{A} 42=5 / 8,831761=0,566139$

$\mathrm{A} 52=1 / 8,831761=0,113228$

$\mathrm{A} 62=3 / 8,831761=0,339683$

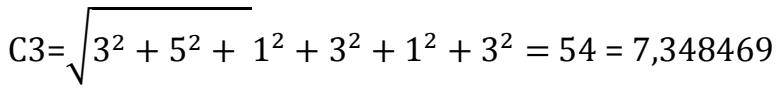

$\mathrm{A} 13=3 / 7,348469=0,408248$

$\mathrm{A} 23=5 / 7,348469=0,680414$

$\mathrm{A} 33=1 / 7,348469=0,136083$

$\mathrm{A} 43=3 / 7,348469=0,408248$

$\mathrm{A} 53=1 / 7,348469=0,136083$

$\mathrm{A} 63=3 / 7,348469=0,408248$

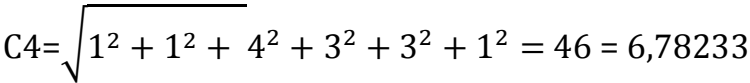

$\mathrm{A} 13=1 / 6,78233=0,147442$

$\mathrm{A} 23=1 / 6,78233=0,147442$

$\mathrm{A} 33=5 / 6,78233=0,73721$

$\mathrm{A} 43=3 / 6,78233=0,442326$

$\mathrm{A} 53=3 / 6,78233=0,442326$

$\mathrm{A} 63=1 / 6,78233=0,147442$

c. Matriks Ternormalisasi

Dari hasil perhitungan di atas maka didapat matriks ternormalisasi $\left(X_{i j}^{*}\right)$ sebagai berikut : 


$$
X_{i j}^{*} x W j=\left[\begin{array}{lllll}
0,130319 & 0,101905 & 0,122474 & 0,014744 \\
0,137559 & 0,101905 & 0,204124 & 0,014744 \\
0,101359 & 0,169842 & 0,040825 & 0,073721 \\
0,115839 & 0,169842 & 0,122474 & 0,044233 \\
0,130319 & 0,033968 & 0,040825 & 0,044233 \\
0,115839 & 0,101905 & 0,122474 & 0,014744
\end{array}\right]
$$

d. Pengurangan Maksimum dan Minimum

Langkah ini untuk menandakan bahwa sebuah atribut lebih penting itu bisa dikalikan dengan bobot yang sesuai (koefisien signifikansi). Dapat dilihat dari tabel 4 berikut:

Tabel 4. Daftar Yi

\begin{tabular}{|c|c|c|c|}
\hline Alternatif & Max(C1+C2+C3) & Min (C4) & Yi=(Max - Min \\
\hline A1 & 0,354699 & 0,014744 & 0,339954 \\
\hline A2 & 0,443588 & 0,014744 & 0,428844 \\
\hline A3 & 0,312026 & 0,073721 & 0,238305 \\
\hline A4 & 0,408155 & 0,044233 & 0,363923 \\
\hline A5 & 0,205112 & 0,044233 & 0,16088 \\
\hline A6 & 0,340219 & 0,014744 & 0,325475 \\
\hline
\end{tabular}

e. Menentukan Ranking

Penentuan ranking dapat dilihat pada tabel 5 berikut:

Tabel 5. Hasil Rangking

\begin{tabular}{|c|c|c|}
\hline Alternatif & Result & Rangking \\
\hline A1 & 0,339954 & 3 \\
\hline A2 & 0,428844 & 1 \\
\hline A3 & 0,238305 & 5 \\
\hline A4 & 0,363923 & 2 \\
\hline A5 & 0,16088 & 6 \\
\hline A6 & 0,325475 & 4 \\
\hline
\end{tabular}

Dari hasil perhitungan di atas, dapat dilihat bahwa A2 merupakan mekanik terbaik dengan nilai tertinggi yaitu 0,4 . Dengan kata lain A2 merupakan mekanik terbaik.

\section{SIMPULAN}

Dari sejumlah rangkaian analisa dan pembahasan yang telah dijelaskan, dapat diambil beberapa kesimpulan, sebagai berikut:

a. Untuk menentukan pemilihan mekanik sepeda motor terbaik bukan hanya berdasarkan kriteria keahlian, namun diperlukan juga kriteriakriteria lain seperti pendidikan, disiplin dan masa kerja.

b. Pemilihan mekanik sepeda motor terbaik ini menggunakan metode Multi Objective Optimization On The Basis Of Ratio Analysis (MOORA), yang menghitung bobot nilai dari setiap kriteria-kriteria dari alternatif-alternatif yang ada.

c. Penentuan mekanik yang terbaik ditentukan dari hasil perankingan yang terbaik dan dapat dipertimbangkan oleh pengambil keputusan. 


\section{DAFTAR PUSTAKA}

[1] M. Safii, "Sistem Pendukung Keputusan Penerima Beasiswa PPA Dan BBM Menggunakan Metode Simple Additive Weighting (SAW)", Jurnal Riset Sistem Informasi dan Teknik Informatika, Vol.2 No.1, 2017.

[2] Ridwan Munawar, Rinda Cahyana, Luthfi Nurwandi, "Model Simulasi Perawatan Sepeda Motor”, Jurnal Tekhik Informatika, Vol. 10 No. 01, 2013.

[3] Dadan Umar Daihani, "Komputerisasi Pengambilan Keputusan", Elex Media Komputindo.Jakarta, 2001

[4] Mesran, R. K. Hondro, M. Syahrizal, A. P. U. Siahaan, R. Rahim, and Suginam, "Student Admission Assessment using MultiObjective Optimization on the Basis of Ratio Analysis (MOORA)," J. Online Jar. COT POLIPT, vol. 10, no. 7, pp. 1 -6, 2017.

[5] S. Rokhman, I. F. Rozi, and R. A. Asmara, "Pengembangan sistem penunjang keputusan penentuan ukt mahasiswa dengan menggunakan metode moora studi kasus politeknik negeri malang," $J$. Inform. Polinema, vol. 3, no. 4, pp. 36-42, 2017.

[6] S. Chakraborty and E. K. Zavadskas, "Applications of WASPAS Method in Manufacturing Decision Making," Informatica, vol. 25, no. 1, pp. 1 $20,2014$. 